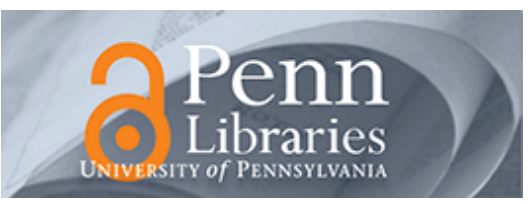

University of Pennsylvania

ScholarlyCommons

$9-2004$

\title{
Addressing the Ethical, Legal, and Social Issues Raised by Voting by Persons with Dementia
}

\author{
Jason H. Karlawish \\ University of Pennsylvania, jason.karlawish@uphs.upenn.edu \\ Richard J. Bonnie \\ University of Virginia - Main Campus \\ Paul S. Appelbaum \\ University of Massachusetts Medical School Worcester \\ Constantine Lyketsos \\ Johns Hopkins University \\ Bryan James \\ Enllow this and additional works at: https://repository.upenn.edu/bioethics_papers \\ Part of the Bioethics and Medical Ethics Commons, Civil Rights and Discrimination Commons, Elder \\ Law Commons, Health Policy Commons, Psychiatric and Mental Health Commons, and the Public Policy \\ See next page for additional authors
}

\section{Recommended Citation}

Karlawish, J. H., Bonnie, R. J., Appelbaum, P. S., Lyketsos, C., James, B., Knopman, D., Patusky, C., Kane, R. A., \& Karlan, P. S. (2004). Addressing the Ethical, Legal, and Social Issues Raised by Voting by Persons with Dementia. Retrieved from https://repository.upenn.edu/bioethics_papers/66

Suggested Citation:

Karlawish J.H., Bonnie R.J., Appelbaum P.S., Lyketsos C., James B., Knopman D., Patusky C., Kane R.A, and Karlan R.S. (2004) Addressing the ethical, legal, and social issues raised by voting by persons with dementia. JAMA Vol. 292(11). pp.1345-50.

http://jama.ama-assn.org/cgi/content/full/292/11/1345

This paper is posted at ScholarlyCommons. https://repository.upenn.edu/bioethics_papers/66

For more information, please contact repository@pobox.upenn.edu. 


\title{
Addressing the Ethical, Legal, and Social Issues Raised by Voting by Persons with Dementia
}

\begin{abstract}
This article addresses an emerging policy problem in the United States participation in the electoral process by citizens with dementia. At present, health care professionals, family caregivers, and long-term care staff lack adequate guidance to decide whether individuals with dementia should be precluded from or assisted in casting a ballot. Voting by persons with dementia raises a series of important questions about the autonomy of individuals with dementia, the integrity of the electoral process, and the prevention of fraud. Three subsidiary issues warrant special attention: development of a method to assess capacity to vote; identification of appropriate kinds of assistance to enable persons with cognitive impairment to vote; and formulation of uniform and workable policies for voting in long-term care settings. In some instances, extrapolation from existing policies and research permits reasonable recommendations to guide policy and practice. However, in other instances, additional research is necessary.
\end{abstract}

\section{Keywords}

dementia, voting, long-term care, competency

\section{Disciplines}

Bioethics and Medical Ethics | Civil Rights and Discrimination | Elder Law | Health Policy | Psychiatric and Mental Health | Public Policy

\section{Comments}

Suggested Citation:

Karlawish J.H., Bonnie R.J., Appelbaum P.S., Lyketsos C., James B., Knopman D., Patusky C., Kane R.A, and Karlan R.S. (2004) Addressing the ethical, legal, and social issues raised by voting by persons with dementia. JAMA Vol. 292(11). pp.1345-50.

http://jama.ama-assn.org/cgi/content/full/292/11/1345

\section{Author(s)}

Jason H. Karlawish, Richard J. Bonnie, Paul S. Appelbaum, Constantine Lyketsos, Bryan James, David Knopman, Christopher Patusky, Rosalie A. Kane, and Pamela S. Karlan 


\title{
Addressing the ethical, legal, and social issues raised by voting by persons with dementia
}

\author{
Jason H. Karlawish, MD \\ Richard J. Bonnie, JD \\ Paul S. Appelbaum, MD \\ Constantine Lyketsos, MD \\ Bryan James, MBioethics \\ David Knopman, MD \\ Christopher Patusky, JD \\ Rosalie A. Kane, $\mathrm{PhD}$ \\ Pamela S. Karlan, JD
}

Published in the Journal of the American Medical Association, Volume 292, September 2004, pages 1345-1350. 


\section{ABSTRACT}

This article addresses an emerging policy problem in the United States participation in the electoral process by citizens with dementia. At present, health care professionals, family caregivers, and long-term care staff lack adequate guidance to decide whether individuals with dementia should be precluded from or assisted in casting a ballot. Voting by persons with dementia raises a series of important questions about the autonomy of individuals with dementia, the integrity of the electoral process, and the prevention of fraud. Three subsidiary issues warrant special attention: development of a method to assess capacity to vote; identification of appropriate kinds of assistance to enable persons with cognitive impairment to vote; and formulation of uniform and workable policies for voting in longterm care settings. In some instances, extrapolation from existing policies and research permits reasonable recommendations to guide policy and practice. However, in other instances, additional research is necessary. 


\section{INTRODUCTION}

Since the founding of the US republic, social and political movements have substantially expanded the right to vote. ${ }^{1}$ Most recently, these efforts have focused on persons with physical disabilities. ${ }^{2-\underline{3}}$ But efforts to extend the franchise as broadly as possible have largely overlooked an important policy problem-how to ensure meaningful access to the ballot box for persons with cognitive disabilities.

Among the many conditions that cause cognitive impairments, dementia presents particularly concerning issues. Because it is progressive, many individuals who have it will cross a threshold from being capable to being incapable of voting. Voting rates are highest among persons aged 65 to 74 years, ${ }^{4}$ and age is the chief risk factor for dementia.

Estimates suggest that by 2050 , there will be about 15 million persons with dementia in the United States. $\frac{5}{}$

Persons with dementia who remain capable of voting and want to do so may be denied this right because their caregivers incorrectly assume that such persons lack capacity or because they lack access to voting technologies tailored to cognitive disabilities. Alternatively, persons who have lost the capacity to vote may vote anyway, or others, such as health care professionals or family members, may cast their ballots for them, thereby compromising the integrity of the system. This concern may be particularly pronounced for local elections, where a small number of votes are more likely to affect the results, but the events in Florida during the 2000 US presidential election show that even national elections can turn on very few votes. $\underline{6}$

Unfortunately, society has not adequately addressed issues relating to voting by persons with dementia. This article addresses 3 critical issues that require attention: development of a method to assess the capacity to vote; identification of appropriate kinds of assistance to enable persons with cognitive impairment to vote; and formulation of uniform policies for voting in long-term care settings. In some instances, existing policies and research permit reasonable recommendations. However, other issues cannot be addressed without additional research and public discussion.

\section{The Capacity to Vote}

Electoral laws in the United States are a patchwork of federal, state, and local enactments and court decisions. Although federal protection of the right to vote has expanded dramatically over the past 50 years, federal laws acknowledge traditional state authority to define voter qualifications relating to residency, citizenship, criminal record, and mental capacity. ${ }^{\underline{(p p 16-140)}}$ The National Voter Registration Act of 1993 specifically acknowledges the traditional state prerogative to disenfranchise persons "by reason of criminal conviction or mental incapacity."요

States laws vary substantially. About two thirds of the states and the District of Columbia disenfranchise individuals on the basis of legal classifications not specifically related to the capacity to vote. The typical provision precludes registration by persons who have been adjudicated as "insane" or mentally incompetent or incapacitated or who are under a guardianship order. ${ }^{9}$ Only 8 states focus their exclusionary criteria specifically on the capacity to vote (Connecticut, Florida, Iowa, Massachusetts, New Mexico, Ohio, Oregon, and 
Wisconsin), but none of these states identifies a standard to assess an individual's capacity to vote.

There are several points in the path to casting a ballot at which one of these disqualification provisions might disenfranchise an individual. First, registration forms may ask for information-such as whether an individual is under guardianship-that then leads to the application being rejected. Second, when a person attempts to register or to vote, a voting official might doubt his capacity and refuse to supply a registration form or a ballot. Third, staff at long-term care facilities or family caregivers may serve as gatekeepers, deciding whether to inform individuals of their right to vote and whether and how to assist them in registering or voting. Such gatekeepers might systematically assume that some or all persons with dementia lack the capacity to vote based on legal status, stereotypical judgments, or family preferences. Alternatively, these persons might assume that everyone who expresses a desire to vote is competent to do so.

The problem with both the traditional statutory exclusions and the informal gatekeeping determinations is that they are likely incompatible with well-developed principles of contemporary mental health law and ethics. Under contemporary principles, persons' decision-making prerogatives should not be denied based on diagnosis or history alone. Instead, assessment of decision-making ability should focus on specific functional capacities wherever possible. $\frac{10}{}$ Given the fundamental character of the right to vote under modern constitutional doctrine, laws disqualifying individuals without a specific determination of incapacity to vote may violate the federal constitution as well as the Americans With Disabilities Act. $\underline{11}$

Doe $v$. Rowe, a recent decision by a federal district court in Maine, illustrates this point. $\underline{12}$ Doe struck down a provision of the Maine constitution that disenfranchised persons "under guardianship for reasons of mental illness." Three persons in that category challenged the provision under the Fourteenth Amendment of the federal Constitution and the Americans with Disabilities Act. The court held that Maine's provision was impermissibly overbroad. Many persons under guardianship for mental illness may nevertheless adequately understand the nature and effect of casting a ballot. At the same time, by disenfranchising only persons under guardianship for "mental illness" while allowing unrestricted participation by persons under guardianship for other reasons-eg, coma, head trauma, or mental retardation-the provision arbitrarily discriminated against people with mental illness. In addition, the court held that Maine failed to provide due process to persons who faced the prospect of losing the right to vote.

One of the Doe court's important contributions was to clarify the meaning of "capacity to vote." Under the court's ruling, a person has the capacity to vote if he or she understands the nature and effect of voting and has the capacity to choose among the candidates and questions on the ballot. This standard is a constitutionally appropriate model for legal reform. It is preferable to other proposed standards, such as the ability to provide the information needed to register to vote, $\underline{13}$ because while registration is a necessary prerequisite to voting, the ability to provide one's name and address does not speak directly to the task that a voter will undertake in the voting booth.

At the same time, the Doe standard is preferable to more demanding standards that would disqualify voters who lack the capacity to cast an "intelligent" vote or to understand the precise issues on the ballot and exercise a reasoned choice. The US experience with "literacy" tests inquiring about detailed issues of constitutional law and political science amply demonstrates that any standard that probes more deeply into a person's electoral 


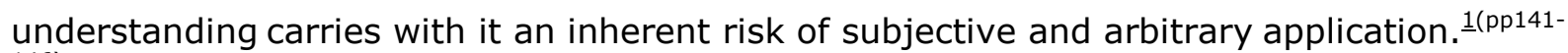

146) Moreover, even if such a standard could be consistently and fairly applied, contemporary legal doctrine rejects restrictions based on factors such as education or particular knowledge as incompatible with our commitment to a universal franchise. Many individuals who are entirely competent may base their votes on what others may regard as "irrational" considerations, but their choices are respected nonetheless.

But as useful as the Doe standard is to assess the capacity to vote, 4 steps must be taken to put it into practice. First, all states should revise their statutes regarding the capacity to vote to specify that an adult who lacks the capacity to understand the nature and effect of voting and to make an electoral choice may be precluded from voting, and that an adult who is subject to a guardianship order retains the right to vote unless the guardianship order explicitly provides otherwise.

Second, the Doe standard must be operationalized in an instrument to assess the abilities to understand the nature and effect of voting and to make a choice. Just as standardized instruments have been developed to assess a person's capacity to consent to treatment and research, $\underline{\underline{14}-\underline{15}}$ poll workers, judges, professional caregivers, and family members need a similar instrument to assess capacity to vote. We are currently testing an instrument that operationalizes the Doe standard. $\frac{16}{}$ To assess whether a person understands the nature of voting, the person is asked to imagine that it is election day for governor of his or her state and is then asked how the people of the state will pick the next governor (the correct answer is that people will vote). To assess whether a person understands the effect of voting, the person is asked how it will be decided who won the election (the correct answer is that whoever gets the most votes wins). The individual is then presented with a short description of 2 candidates and is asked to choose 1 of the candidates. The candidate the person chooses is, of course, irrelevant. The critical issue is whether the person is able to express a choice.

Third, constitutional due process requires developing fair procedures for implementing an exclusionary standard. .12 Nondiscriminatory procedures for applying a test of voter capacity at the voter registration facility and at the time of voting are needed. For example, if a question is raised about a particular person's capacity to vote at the polling place, a poll worker might ask the questions described above. Persons who are unable to answer such questions correctly might then undergo a more detailed assessment. However, prior to implementing such a procedure, discussion is needed as to whether such a critical decision should be delegated to poll workers acting in the heated, partisan environment of election day, rather than being entrusted to officials at some point earlier in the process, during which time it is possible to have effective review of the decision to strip a citizen of his or her right to vote.

Fourth, public education is needed. The state's electorate twice ratified the discriminatory provision in Maine's constitution that the Doe case struck down. 17 The public needs to learn about the wrongfulness of restrictions based on labels such as "mental illness" and the importance of focusing on the particular abilities involved in voting. 


\section{Providing Assistance to Persons With Dementia}

As dementia progresses, patients invariably need assistance from other people, commonly called caregivers, to perform activities of daily living, make decisions such as whether to enroll in research, and interact with health care professionals. $\underline{18-19}$ These caregivers will also need to address issues that arise concerning voting, both to assure themselves that patients with the requisite capacity and inclination are able to vote and to take appropriate action when such capacity is in doubt.

The role of the caregiver in voting has received limited study. Persons cared for by a spouse are more likely to vote than persons cared for by a nonspousal caregiver, and whether a patient votes is strongly correlated with his or her caregiver's attitudes about the appropriateness of voting by cognitively impaired individuals. $\underline{20-21}$ These findings suggest that spouses and health care professionals need guidance in deciding whether and how to assist impaired individuals in voting.

Voting by secret ballot was first introduced in the 19 th century..$^{1(p 142)}$ Before then, ballots were often coded or otherwise completed in a manner permitting others to observe a person's vote. While the secret ballot reduces the risk of coercion by organized groups such as unions, employers, and political machines, it also has the effect of disenfranchising many individuals who need assistance to vote. Although the secret ballot is the norm in the United States, federal law now permits people to have assistance when voting. Most of the extant regulations and guidance relating to assistance pertain to persons with physical handicaps such as blindness and immobility. ${ }^{2-3}$ Considerably less attention has been paid to the appropriate degree of assistance for persons with cognitive impairment.

At least 1 type of assistance in voting is not appropriate for family caregivers or other persons caring for patients with dementia: voting on the person's behalf as a proxy decision maker. Although it is well established legally and ethically that proxies are authorized to make decisions for persons who cannot make decisions for themselves in medical contexts, $\stackrel{22}{2}$ a proxy is not permitted to vote on behalf of another person. Some may think that this prohibition "disenfranchises" persons with dementia, especially persons with longstanding and well-articulated political views that are well known to a surrogate who is exercising a "substituted judgment" or even executing a "voting advance directive." For example, in the month following the 2000 US presidential election, a spousal caregiver contributing to an Alzheimer disease e-mail exchange wrote, "Since we have been married, he has always voted a straight Democratic ticket so I did the same for him ... I do not feel guilty. I feel that he is being represented since he certainly pays enough income tax, has

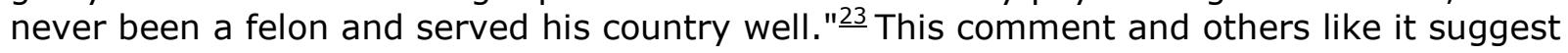
that some family caregivers consider it within their prerogative to vote on behalf of the person for whom they otherwise serve as a recognized proxy.

Notwithstanding the broad scope of proxy decisions by family caregivers for persons with dementia in other contexts, ${ }_{19}$ proxy voting is legally impermissible. Unlike medical and financial decisions, the act of voting in a democratic polity is an incident of citizenship and an inalienable right. Citizenship creates certain obligations and opportunities that cannot be delegated, such as submitting to a military draft or serving on a jury. Although a person has the prerogative to vote as another person recommends, the person cannot "assign" his or her right to vote to someone else.

Within this important constraint, what types of assistance are appropriate at a polling place and in the casting of an absentee ballot? The same factors that make voting easier can also 
make fraud or coercion more likely. For example, permitting an assistant to enter the voting booth with a disabled voter may be necessary to enable the voter to read the ballot or mark his choice, but once the curtain is drawn, the assistant has the opportunity to act without being observed and might cast the ballot for the candidate he or she prefers, rather than for the voter's choice. Similarly, with respect to absentee ballots, voting at home may be far more practical for a disabled voter than traveling to an inaccessible polling place during a limited time period on election day, but voting at home takes place without any supervision by neutral polling officials and may render a disabled voter completely dependent on a caregiver whose preferences differ from his or hers.

Absentee voting is already a prevalent practice among elderly voters. One national study found that absentee voting rates among voters older than 65 years were more than twice as high as absentee voting rates among voters between ages 25 and 64 years. ${ }^{24}$ Moreover, absentee voting rates are rising as states liberalize voters' opportunities to cast absentee ballots (eg, California) or permit voting by mail for all state elections (eg, Oregon). Data from a recent election in Los Angeles found that while only $8 \%$ of 26 - to 35 -year-old voters requested absentee ballots, $25 \%$ of those older than 51 years requested them. $\underline{25}$

Absentee voting is a significant source of alleged fraud in the electoral process; for example, absentee ballots account for $60 \%$ of all vote fraud allegations in Chicago and were the source of substantial fraud allegations in recent UK elections. $\underline{26-27}$ A major technique of absentee ballot-based fraud involves third parties casting ballots in the names of individuals who remain on the registration rolls but who, for whatever reason, do not seek to vote themselves. Thus, the presence of names of individuals whose progressive mental deterioration has left them unable to vote can provide a pool of potentially usable votes for third parties to exploit. Further study is needed to determine whether there are ways of reducing the risk of fraud or coercion while fully protecting the voting rights of disabled but capable individuals.

In the absence of such studies, it is necessary to make provisional judgments about the types of assistance that a person can legitimately provide to a cognitively impaired voter. Neutral presentations of candidates' party affiliations or other identifying information can be helpful to voters without infringing on their rights or compromising the integrity of their ballots in any way. Whether arguments for or against candidates can be presented to voters by persons assisting them without biasing their choices is less certain. Official voter pamphlets, with approved candidate or ballot proposition statements, may provide an especially appropriate form of information. In any case, however, persons assisting cognitively impaired voters should not be injecting their own preferences into their interactions with voters, such as by suggesting how the ballot should be cast. Current voting assistance provisions, for example, forbid assistance by a voter's employer or union representative precisely because of a fear that those relationships may create a greater risk of undue influence than would assistance by a person more responsive to the voter's own preferences. We think that concerns about undue influence are not substantial enough to justify a rule precluding caregivers from providing assistance, but persons who assist voters should be given specific guidance by election officials regarding what is permissible and what is not.

Persons providing assistance should also be aware of the threshold of competence. A requirement that only voting officials can make judgments regarding incompetence to vote would be impractical. Family caregivers and long-term care staff inevitably serve a screening role. Difficult cases are most likely to arise when they are making an effort to facilitate voting by elderly citizens who have not independently expressed an interest in voting. To 
address such cases, persons assisting a cognitively impaired person applying for an absentee ballot or going to a polling place should have access to a simple, standardized instrument for assessing capacity to vote. When they have a significant doubt about the impaired person's capacity to vote, they should be encouraged to use the instrument. If this assessment reveals doubt about competence to vote, it is probably appropriate to regard the impaired person as incompetent to vote, at least until a more authoritative determination is available.

We emphasize that election officials should provide this kind of guidance in written instructions available to caregivers and staff of long-term care facilities. In addition, a mechanism to obtain direct assistance from election personnel may be helpful in cases in which there is uncertainty about a person's capacity to vote.

Ballots should be made as accessible as possible for all voters, including persons whose cognitive impairments and concomitant deficits can lead to misunderstanding of information. One of the complaints about the "butterfly ballot" used in Florida's Palm Beach County in 2000 was that the ballot was confusing and caused people to make mistakes, casting their votes for a candidate other than the one they intended. $\underline{28}$ The format of the ballot and its mechanism for casting a vote should minimize as much as possible complex visual-spatial representation. In addition, the type size for printed materials should be reasonably large and the ballot should clearly state how persons unable to read the ballot can obtain a more readable ballot. A bill recently introduced in the Illinois legislature would place photographs of presidential candidates on all ballots. $\underline{29}$ Whatever its overall merit, such a change might be particularly useful for persons with mild to severe Alzheimer disease, who are better able to recognize pictures of the candidates in the US presidential election than to identify the candidates based on free recall. $\underline{21}$ The effectiveness of ballot design changes in decreasing confusion and mistaken voting should be evaluated.

\section{Developing Workable Policies for Voting in Long-term Care Facilities}

Persons with dementia typically need assistance in performing activities of daily living and may require 24-hour supervision. In many cases, this care is provided in a long-term care residential setting, such as a nursing home or an assisted-living facility.

Nursing homes and, to a lesser extent, assisted-living facilities concentrate groups of individuals who have cognitive impairment. $\underline{30} \underline{-31}$ They do this within an institutional culture where staff often have a significant degree of authority over the residents' decisions about matters as disparate as taking meals and voting. $\underline{32}$ Hence, these settings magnify all of the aforementioned problems. Unwarranted assumptions about lack of capacity to vote and the failure to provide appropriate assistance may deny capable and willing residents a meaningful opportunity to vote. At the same time, efforts to facilitate voting can also increase the risk of "incompetent" voting and fraud. In close elections, these problems could affect the outcome.

Inappropriate voting has been documented in long-term care settings. Most of the known cases focus on improper registration for or casting of absentee ballots. $\frac{33}{\text { Although federal }}$ nursing home regulations require facilities to respect residents' rights, the regulations do not provide any guidance on the steps needed to implement the right to vote. $\frac{34}{\text { Some states or }}$ counties have issued guidelines for voting in long-term care facilities. Our preliminary survey of 17 state boards of elections found that 10 have guidelines for voting in long-term care. 
The content of these guidelines varies. Some guidelines require election officials to engage in outreach only if a facility meets a threshold number of residents or absentee voters, while others require election officials to supervise voting in all cases. Some guidelines give most of the responsibility to facility staff, acting with minimal supervision by election officials, while others confer extensive responsibilities on election officials for all aspects of registration and voting.

Although we favor uniform guidelines for voting in long-term care, little information is currently available concerning the effectiveness of existing guidelines in promoting participation and limiting fraud. A recent study comparing long-term care voting practices in 2 Maryland counties, 1 with guidelines and 1 without them, suggests that guidelines involving election officials may improve registration and voter turnout, ${ }^{33}$ but recommending specific guidelines would be premature in the absence of a better understanding of how voting actually occurs in long-term care settings.

Uniform policies and practices to govern voting in long-term care need to take into account that staff already face many other tasks as well as the propriety of assigning them a substantial role in the electoral process. One possibility is to assign responsibility to election officials for notifying long-term care staff of the deadlines for registration and absentee ballot applications, delivering absentee ballots and polling booths to a facility, resolving questions of voting capacity, and conducting voting at the facility. This approach may provide the greatest assurance that all capable residents who want to vote have the opportunity to vote, while at the same time placing the burden on election officials to detect voters who lack the requisite capacity. By increasing oversight of the process, it may also reduce opportunities for fraud.

\section{Conclusion}

The ethical, legal, and social challenges posed by voting by persons with dementia warrant concurrent steps in 3 areas. First, state laws should be changed to conform to modern constitutional principles and to incorporate the test for competence to vote enunciated in Doe $v$ Rowe. Voting officials should take the necessary steps to educate the public regarding the applicable law, to provide guidance regarding assessment of capacity to vote, and to utilize a standardized instrument that is brief and simple to administer and score. Second, observational studies and surveys of potential voters and their caretakers are needed to inform the development of rules for assisting voters who have dementia and other cognitive impairments. Some forms of assistance and redesign of ballots may be especially helpful to cognitively impaired voters, and, conversely, some techniques may be ineffective or especially prone to abuse. Finally, while uniform policies are needed for voting in long-term care, these policies should be informed by observational and survey studies that identify current problems and suggest where protections for and assistance to residents are most needed. Policies that are developed should be monitored and refined based on evidence of effectiveness. 


\section{AUTHOR INFORMATION}

Corresponding Author: Jason $\mathrm{H}$. Karlawish, MD, Institute on Aging, University of Pennsylvania, 3615 Chestnut St, Philadelphia, PA 19104 (jasonkar@mail.med.upenn.edu).

Funding/Support: This article was produced as part of "Developing Practical Guidelines for Voting by Persons With Dementia," a project supported by a grant from the Greenwall Foundation, New York, NY, and the Virginia Brown Fellowship for Aging and Stroke Research, Philadelphia, Pa.

Role of the Sponsor: The study's sponsors had no role in the design and conduct of the study, in the collection, analysis, and interpretation of the data, or in the preparation, review, or approval of the manuscript.

Acknowledgment: We thank Dean Drizin and Rebecca Shore for their assistance in research and assembling materials and David Drachman, MD, for his contribution to the project.

Author Affiliations: Department of Medicine, Center for Bioethics (Dr Karlawish), Department of Medicine (Mr James), and Fels Institute of Government (Mr Patusky), University of Pennsylvania, Philadelphia (Dr Karlawish); Schools of Law and Medicine and Institute of Law, Psychiatry and Public Policy, University of Virginia, Charlottesville (Mr Bonnie); Department of Psychiatry, University of Massachusetts Medical School, Worcester (Dr Appelbaum); Division of Geriatric Psychiatry and Neuropsychiatry, Department of Psychiatry, Johns Hopkins University, Baltimore, Md (Dr Lyketsos); Alzheimer's Disease Research Center, Department of Neurology, Mayo Clinic, Rochester, Minn (Dr Knopman); Long-term Care Resources Center, School of Public Health, University of Minnesota, Minneapolis (Dr Kane); and Stanford University School of Law, Stanford, Calif (Ms Karlan). 


\section{REFERENCES}

1. Keyssar A. The Right to Vote: The Contested History of Democracy in the United States. New York, NY: Basic Books; 2000

2. Voting Accessibility for the Elderly and Handicapped Act of 1984 . Pub L No. 98-435, 98 Stat 1678 (codified as amended at 42 USC \$1973ee) (1984).

3. Help America Vote Act of 2002. Pub L No. 107-252, 116 Stat 1666 (to be codified at 42 USC \$15301-15545) (2002).

4. Administration on Aging, Department of Health and Human Services. Announcements: Older Americans Month. Available at: http://www.aoa.gov/press/oam/May 2003/census.asp 2003. Accessed August 18, 2003.

5. Hebert LE, Scherr PA, Bienias JL, Bennett DA, Evans DA. Alzheimer disease in the US population: prevalence estimates using the 2000 census. Arch Neurol. 2003;60:1119-1122.

6. Federal Elections Commission. Federal Elections 2000. Election Results for the US President, the US Senate and the US House of Representatives. Available at: http://www.fec.gov/pubrec/fe2000/cover.htm. Accessed August 13, 2004.

7. Issacharoff S, Karlan PS, Pildes RH. The Law of Democracy: Legal Structure of the Political Process. 2nd ed. New York, NY: Foundation Press; 2001.

8. The National Voter Registration Act of 1993 ("The Motor Voter Act"). Pub L No. 103-31, 107 Stat 77 (codified as amended at 42 USC 1973gg) (1993).

9. Federal Elections Commission. National Registration Form. Available at: http://www.fec.gov/votregis/pdf/nvra.pdf 2004. Accessed April 21, 2004.

10. Moye J. Guardianship and conservatorship. In: Grisso T, Borum R, Edens JF, Moye J, Otto RK. Evaluating Competencies. New York, NY: Kluwer Academic Publishers; 2002:309389.

11. The US Equal Employment Opportunity Commission. The Americans with Disabilities Act of 1990, Titles I and V. Available at: http://www.eeoc.gov/laws/ada.html. Accessed August $14,2003$.

12. Doe v Rowe, No. 00-CV-206-B-S, 2001 US Dist LEXIS 11963, 156 F Supp 2d 35 (D Me 2001).

13. Sales BD, Powell DM, Duizend RV, et al. Voting rights. In: Disabled Persons and the Law. Vol 1. New York, NY: Plenum Press; 1982:99-112.

14. Appelbaum PS, Grisso T. The MacArthur Competence Assessment Tool-Clinical Research. Sarasota, Fla: Professional Resources Press; 2000.

15. Grisso T, Appelbaum PS. The MacArthur Competence Assessment Tool-Treatment. Sarasota, Fla: Professional Resources Press; 1998. 
16. University of Pennsylvania Alzheimer's Disease Center. Developing practical guidelines for voting by persons with dementia. Available at: http://www.uphs.upenn.edu/adc/. Accessed June 17, 2004.

17. Judge: mentally ill can vote. Newsday. August 12, 2001:A22.

18. Karlawish JH, Casarett D, Klocinksi J, Sankar P. How do AD patients and their caregivers decide whether to enroll in a clinical trial? Neurology. 2001;56:789-792.

19. Hirschman KB, Xie SX, Feudtner C, Karlawish JH. How does an Alzheimer's disease patient's role in medical decision-making change over time? J Geriatr Psychiatry Neurol. 2004; 17:55-60.

20. Karlawish JH, Casarett DA, James BD, Propert KJ, Asch DA. Do persons with dementia vote? Neurology. 2002;58:1100-1102.

21. Ott BR, Heindel WC, Papandonatos GD. A survey of voter participation by cognitively impaired elderly patients. Neurology. 2003;60:1546-1548.

22. Buchanan AE, Brock DW. Deciding for Others: The Ethics of Surrogate Decision Making. Cambridge, England: Cambridge University Press; 1989

23. The Alzheimer Page. November 2000. Available at:

http://www.adrc.wustl.edu/archives/html/alzheimer/2000-11/msg00138.html. Accessed August 13, 2004.

24. Task Force of the National Commission on Federal Election Reform. To assure pride and confidence in the electoral process: Task Force reports to accompany the Report of the National Commission on Federal Election Reform. Charlottesville, Va: Miller Center of Public Affairs; 2001.

25. Alvarez M, Hall TE. Whose Absentee Votes are Counted? Caltech/MIT Voting Technology Project Working Paper. Available at: http://www.vote.caltech.edu/Reports/vtp WP4.pdf. 2003. Accessed July 20, 2004.

26. Tate A. Voter fraud not absent in Chicago. Chicago Reporter. November/December $2000 ; 29: 10-13$.

27. Sherman J, Coates S, Kennedy D. Cheating claims shake faith in all-postal voting. London Times. June 11, 2004:11.

28. Pressley SA, Lardner G Jr. In a confused Palm Beach County, complaints came early and often. Washington Post. November 11, 2000:A1.

29. State of Illinois 92nd General Assembly Legislation. An act concerning elections. Available at:

http://www.legis.state.il.us/legislation/legisnet92/hbgroups/PDF/920HB0496.pdf. Accessed August 14, 2003.

30. Magaziner J, German P, Zimmerman SI, et al, Epidemiology of Dementia in Nursing Homes Research Group. The prevalence of dementia in a statewide sample of new nursing 
home admissions aged 65 and older: diagnosis by expert panel. Gerontologist. 2000;40:663-672.

31. Rosenblatt A, Samus Q, Steele C, et al. The Maryland Assisted Living Study: prevalence, recognition and treatment of dementia and other psychiatric disorders in the assisted living population of central Maryland. J Am Geriatr Soc. In press.

32. Goffman E. Asylums: Essays on the Social Situation of Mental Patients and Other Inmates. Chicago, Ill: Aldine Publishing Co; 1961.

33. O'Sullivan JL. Voting and nursing home residents: a survey of practices and policies. $J$ Health Care Law Policy. 2002;4(2):325-353. PENNTEXT

34. Centers for Medicare and Medicaid Services. Requirements for States and Long Term Care Facilities. Subpart B-Requirements for Long Term Care Facilities, 66 Federal Register 512 (2001) (codified at 42 CFR \$483.10). 